Research Paper

\title{
Maternal Outcomes According to Placental Position in Placental Previa
}

\author{
Dong Gyu Jang, Ji Sun We, Jae Un Shin, Yun Jin Choi, Hyun Sun Ko, In Yang Park, Jong Chul Shin $\bowtie$
}

Department of Obstetrics and Gynecology, School of Medicine, The Catholic University of Korea, Seoul, Korea

Corresponding author: Jong Chul Shin, Department of Obstetrics \& Gynecology, Seoul St. Mary's Hospital, 505 Banpo-dong, Seocho-gu, Seoul, 137-701, Korea. Tel: 82-2-2258-6169; Fax: 82-2-595-1549; E-mail: jcshin@catholic.ac.kr

(๑) Ivyspring International Publisher. This is an open-access article distributed under the terms of the Creative Commons License (http://creativecommons.org/ licenses/by-nc-nd/3.0/). Reproduction is permitted for personal, noncommercial use, provided that the article is in whole, unmodified, and properly cited.

Received: 2011.06.23; Accepted: 2011.07.20; Published: 2011.07.23

\begin{abstract}
Purpose: The purpose of this retrospective cohort study was to elucidate whether the location of placenta below uterine incision in cesarean section is important in the development of maternal complications in placenta previa patients.

Methods: The study was conducted on 409 patients 414 parturition at 3 hospitals in affiliation with the Catholic Medical Center, Seoul, Korea from May 1999 to December 2009. The subjects were divided to two groups: the group whose placenta was located in the anterior portion of the uterus (anterior group) and the group whose placenta was located in the posterior portion of the uterus (posterior group). And then they are compared to each other. Logistic regression was used to control for confounding factors.

Results: In the anterior group, regardless of confounding factors, the incidence of excessive blood loss (OR 2.97; 95\% CI: 1.64-5.37), massive transfusion (OR 3.31; 95\% CI: 1.33-8.26), placental accreta (OR 2.60, 95\% CI: 1.40-4.83), and hysterectomy (OR 3.47, 95\% CI: 1.39-8.68) was higher.

Conclusion: Sonographic determination of the placental position where its location beneath the uterine incision is very important to predict maternal outcomes in placenta previa patients, and such cases, close attention should be paid for massive hemorrhage.
\end{abstract}

Key words: hemorrhage, hysterectomy, maternal outcomes, placental accreta, placental position, placental previa

\section{Introduction}

Generally, the frequency of placental previa is 4 in 1,000 patients. Risk factors are old age, multiparity, previous cesarean delivery, abortion, smoking, cocaine, and male fetus [1]. In previa patients, postpartum hemorrhage is substantial, which increases maternal complications [2]. Risk factors for massive hemorrhage and transfusion are old age, abortion, previous cesarean section, uterine myoma, increased BMI, increased neonatal weight, and complete previa [3-5]. Also, risk factors for peripartum hysterectomy are previous cesarean section, history of abortion, and complete previa [6].
Until now, placental previa has been classified by the degree of encroachment upon the internal cervical os, because most studies reported that in complete previa, the possibility of massive perinatal hemorrhage, transfusion, placental accreta, and hysterectomy are strong [3,7-10]. But most obstetricians have concerns about massive hemorrhage not only when complete previa exists, but also when placenta is located on the anterior portion of the uterus, beneath the cesarean incision site $[11,12]$. Yet, the subject has rarely been studied; therefore, the authors have sought for statistical significance that the location of 
placenta is an independent prognostic factor of maternal pregnancy outcomes.

\section{Patients and methods}

\section{Subjects}

A study was conducted on women diagnosed as placenta previa by ultrasonography and delivered at Seoul St. Mary's Hospital, St. Vincent's Hospital and Yeouido St. Mary's Hospital in affiliation with the Catholic Medical Center, Seoul, Korea between May 1, 1999, and December 31, 2009. 143 deliveries of 142 placental previa patients among total 10,840 deliveries were at the Seoul St Mary's hospital, 95 deliveries of 95 placental previa patients among 9,949 deliveries were at the St Vincent's Hospital and 322 deliveries of 318 placental previa patients among 14,241 deliveries were at the Yeouido St Mary's Hospital.

Among the entire 560 deliveries of 555 patients, excluding 30 patients with vaginal delivery, 10 multiple pregnancy patients, 4 patients with the placental malformation ( 3 succenturiated placentas, 1 accessory placenta), 24 patients that the location of placenta was not clearly shown in medical records, 41 patients with the placental main body located in the lateral body, and 37 patients with the placental main body located in the central portion, 414 deliveries of 409 patients were examined on obstetric medical records retrospectively, and the previa cases with the placental main body located in the anterior uterine body were assigned as the anterior group, and those with the placenta located in the posterior portion of uterus were assigned as the posterior group, and then these two groups were compared.

This study was approved by the clinical study medical ethics committee of Catholic Medical Center (XC10RIMI0126V).

\section{Methods}

Based on the review of medical database, maternal age, parity, delivery methods, maternal past history (miscarriage, uterine surgery), diseases associated with pregnancy (myoma, endometriosis), prenatal ultrasonography and the findings of surgery were reviewed in all patients.

To compare maternal outcomes, the hemoglobin level of prior to surgery, 1 day after surgery, and 3 days after surgery, the amount of transfusion during surgery, estimated blood loss during operation, placental accreta, hysterectomy, myomectomy, placental abruption, disseminated intravascular coagulation, emergency cesarean section and maternal death were assessed.
Excessive blood loss was defined as the estimated blood loss higher than $1000 \mathrm{~mL}$ during surgery, and massive transfusion was defined as the transfusion of 10 packs of Packed Red Cells or whole blood during or after surgery.

Placenta previa in our study was all confirmed by last transvaginal sonographic exam prior to delivery. In addition to the location in the anterior portion or posterior portion of uterus, they were classified by sonographers blinded to the outcomes when sonographic exam according to the level of the placental coverage over internal os of cervix as complete, partial, marginal, low lying, and vasa previa [10]. Most of last sonographic exams were done on the day of operation (and not before one week) and when the placental main body was located in central or lateral portion of uterine body, these cases were excluded in this study.

\section{Statistical methods}

Statistical analysis on study results was performed by the application of the SAS version 8 (SAS Institute, Berkley, CA, USA). For the comparison of continuous variables, depending on whether it is the normal distribution or not, independent T-test or the non-parametric method Mann- Whitney $U$ test was applied. For categorical variables, chi-square test or Fisher's exact test was applied.

For the difference of maternal complications, by logistic regression analysis, parity, previous abortion, previous cesarean section and complete previa were adjusted.

$P<0.05$ was determined to be statistically significant.

\section{Results}

\section{Maternal characteristics}

Among 35030 deliveries, placenta previa case was 560 , which was $1.5 \%$ of the total count.

Of the 414 deliveries that were included, the maternal characteristics were compared between the anterior and the posterior group. When compared, maternal age, the number of abortion and the history of abdominal surgery excluding cesarean section showed no significant difference. And also these two groups showed no significant difference in maternal diseases such as endometriosis, myoma and incidence of myomectomy performed simultaneously during cesarean section. Moreover, the level of placental coverage over internal os of cervix described no statistical difference between these two groups.

On the other hand, parity $>2$ cases were significantly more common in anterior group in comparison 
with parity $=0$ (OR 2.14; 95\% CI: 1.19-3.87). In addition, there were significantly more cases in anterior group with history of previous cesarean section $>2$ in comparison with previous cesarean section $=0(\mathrm{OR}$ 4.23; 95\% CI: 1.99-8.99) (Table 1).

\section{Maternal pregnancy outcomes}

The result of the analysis of maternal complications were evaluated by univariate analysis according to the placental location is shown in Table 2.

Hemoglobin levels before or after surgery were not significantly different between those two groups. Nonetheless, the amounts of PRC or whole blood transfused during surgery were $2.44 \pm 4.34$ packs and $1.15 \pm 2.16$ packs, respectively $(P=0.001)$, and the estimated blood loss during surgery was $1150.79 \pm$ $1610.19 \mathrm{~mL}$ and $686.08 \pm 770.19 \mathrm{~mL}$, respectively $(P<$
0.001), showing that anterior group had more blood loss and more blood transfusion than posterior group.

Furthermore, incidences of placental accreta (OR 2.94; 95\% CI: 1.63-5.29) and hysterectomy (OR 4.24; $95 \%$ CI: 1.77-10.17) were much more common in the anterior group. No significant differences were found in placental abruption, DIC, emergency cesarean section and maternal mortality (Table 2).

Maternal complications were analyzed by logistic regression adjusting for maternal age, parity, previous abortion, previous Cesarean section and complete previa. The results showed that the incidences of excessive blood loss (OR 2.97; 95\% CI: 1.64-5.37), massive transfusion (OR 3.31; 95\% CI: 1.33-8.26), placental accreta (OR 2.60; 95\% CI: 1.40-4.83) and hysterectomy (OR 3.47; 95\% CI 1.39-8.68) were significantly higher in the anterior group (Table 3).

Table 1. Maternal characteristics in placental previa according to placental position

\begin{tabular}{|c|c|c|c|c|c|}
\hline & & Anterior (141) & Posterior (273) & OR $(95 \% \mathrm{CI})$ & Significance \\
\hline \multicolumn{2}{|l|}{ Age (year) } & $32.62 \pm 4.04$ & $32.55 \pm 4.07$ & & 0.831 \\
\hline \multirow[t]{3}{*}{ Parity } & 0 & $50(35.5 \%)$ & $114(41.8 \%)$ & 1 & 0.029 \\
\hline & 1 & $60(42.6 \%)$ & $126(46.2 \%)$ & $1.09(0.69-1.71)$ & \\
\hline & $>=2$ & $31(22.0 \%)$ & $33(12.1 \%)$ & $2.14(1.19-3.87)$ & \\
\hline \multirow[t]{3}{*}{ Abortion } & 0 & $58(41.1 \%)$ & $129(47.3 \%)$ & 1 & 0.327 \\
\hline & 1 & $41(29.1 \%)$ & $80(29.3 \%)$ & $1.14(0.70-1.86)$ & \\
\hline & $>=2$ & $42(29.8 \%)$ & $64(23.4 \%)$ & $1.46(0.89-2.40)$ & \\
\hline \multirow{3}{*}{$\begin{array}{l}\text { Previous } \\
\text { C/Sec }\end{array}$} & 0 & $82(58.2 \%)$ & $198(72.5 \%)$ & 1 & $<0.001$ \\
\hline & 1 & $38(27.0 \%)$ & $63(23.1 \%)$ & $1.46(0.90-2.35)$ & \\
\hline & $>=2$ & $21(14.9 \%)$ & $12(4.4 \%)$ & $4.23(1.99-8.99)$ & \\
\hline \multicolumn{2}{|c|}{ Prepregnant body weight (kg) } & $55.33 \pm 7.54$ & $55.01 \pm 7.21$ & & 0.844 \\
\hline \multirow{2}{*}{\multicolumn{2}{|c|}{$\begin{array}{l}\text { Previous uterine surgery except } \mathrm{C} / \mathrm{sec} \\
\text { endometriosis }\end{array}$}} & $0(0 \%)$ & $4(1.5 \%)$ & $0.99(0.97-1.00)$ & 0.188 \\
\hline & & $2(1.4 \%)$ & $11(4.0 \%)$ & $0.34(0.08-1.57)$ & 0.234 \\
\hline \multicolumn{2}{|l|}{ Myoma } & $2(1.4 \%)$ & $9(3.3 \%)$ & $0.42(0.09-1.98)$ & 0.346 \\
\hline \multicolumn{2}{|c|}{ Myomectomy } & $2(1.4 \%)$ & $6(2.2 \%)$ & $0.64(0.13-3.21)$ & 0.721 \\
\hline \multirow[t]{5}{*}{ previa } & complete & $60(42.6 \%)$ & $107(39.2 \%)$ & 1 & 0.548 \\
\hline & Partial & $16(11.3 \%)$ & $33(12.1 \%)$ & $0.87(0.44-1.70)$ & \\
\hline & marginal & $11(7.8 \%)$ & $36(13.2 \%)$ & $0.55(0.26-1.15)$ & \\
\hline & Low lying & $53(37.6 \%)$ & $96(35.2 \%)$ & $0.99(0.62-1.56)$ & \\
\hline & Vasa previa & $1(0.7 \%)$ & $1(0.4 \%)$ & $1.78(0.11-29.03)$ & \\
\hline
\end{tabular}

Values are expressed as mean \pm SD or number $(\%)$

$\mathrm{C} /$ sec: cesarean section 
Table 2. Univariate analysis of maternal pregnancy outcomes according to placental position in placental previa

\begin{tabular}{|c|c|c|c|c|}
\hline & Anterior (141) & Posterior (273) & OR $(95 \% \mathrm{CI})$ & Significance \\
\hline Preop $\mathrm{Hb}(\mathrm{g} / \mathrm{dL})$ & $11.12 \pm 1.56$ & $11.07 \pm 1.42$ & & 0.619 \\
\hline POD\#1 Hb (g/dL) & $10.23 \pm 1.68$ & $10.15 \pm 1.54$ & & 0.512 \\
\hline POD\#3 Hb (g/dL) & $9.32 \pm 1.37$ & $9.28 \pm 1.43$ & & 0.749 \\
\hline $\begin{array}{l}\text { Transfusioned PRC or whole blood } \\
\text { during operation (packs) }\end{array}$ & $2.44 \pm 4.34$ & $1.15 \pm 2.16$ & & 0.001 \\
\hline EBL (mL) & $1150.79 \pm 1610.19$ & $686.08 \pm 770.19$ & & $<0.001$ \\
\hline Placental accreta & $30(21.3 \%)$ & $23(8.4 \%)$ & $2.94(1.63-5.29)$ & $<0.001$ \\
\hline Hysterectomy & $22(12.4 \%)$ & $10(3.2 \%)$ & $4.24(1.77-10.17)$ & 0.001 \\
\hline Placental abruption & $6(4.3 \%)$ & $4(1.5 \%)$ & $2.99(0.83-10.77)$ & 0.096 \\
\hline DIC & $3(2.1 \%)$ & $3(1.1 \%)$ & $1.96(0.39-9.82)$ & 0.414 \\
\hline Emergency C/Sec & $69(48.9 \%)$ & $111(40.7 \%)$ & $1.40(0.93-2.11)$ & 0.117 \\
\hline Maternal mortality & $0(0 \%)$ & $1(0.4 \%)$ & $1.00(0.99-1.00)$ & 1.000 \\
\hline
\end{tabular}

Values are expressed as mean \pm SD or number $(\%)$

$\mathrm{Hb}$ : hemoglobin

POD: post operation day

PRC: packed red cell

EBL: estimated blood loss

DIC: disseminated intravascular coagulation

C/sec: cesarean section

Table 3. Odds ratio of anterior placental location for developing maternal complications in placental previa (multivariate analysis)

\begin{tabular}{llll}
\hline complications & OR & $95 \%$ CI & Significance \\
\hline Excessive blood loss & 2.97 & $1.64-5.37$ & $<0.001$ \\
Massive transfusion & 3.31 & $1.33-8.26$ & 0.010 \\
Placental accreta & 2.60 & $1.40-4.83$ & 0.002 \\
Hysterectomy & 3.47 & $1.39-8.68$ & 0.008 \\
\hline
\end{tabular}

*: age, parity, previous abortion, previous cesarean section and complete previa are adjusted

\section{Discussion}

It is the first study ever that maternal morbidities significantly increase when placenta is located in the anterior portion of uterus in placenta previa.

In this study, the incidences of complete previa between the two groups were not significantly different, which concurs with the study reported by Tuzovic et al. conducted in 202 patients [13]. It means that anterior placental location is a risk factor that affects pregnancy outcome independent of the level of coverage of internal os of cervix in placental previa.

We strongly believe that the high incidence of anterior previa among high parity especially 2 or more prior cesarean section in this study is associated with placental accreta.
And it was observed that the incidence of placental accreta and hysterectomy is more common in anterior group. It is well known that Placenta accreta is accompanied with approximately $7 \sim 10 \%$ of all cases of placenta previa, and in such cases, the chances of massive hemorrhage and hysterectomy is high $[8,9,14]$.

Usta et al. compared 22 placental previa patients with placental accreta and 325 patients without accreta, and reported that the frequency of maternal morbidity such as blood loss, transfusion, hysterectomy, etc. was higher in cases with accreta than those cases without accreta.

However, unlike our research, they reported that the frequency of anterior placenta of the group asso- 
ciated with placental accreta was not significantly different from the group without accreta [15].

That can be due to the facts that in the study conducted by Usta et al., the incidence of accreta in anterior placenta group was $8.9 \%$, and the other group was $5.1 \%$ ( $p$ value 0.258 ), which was lower than the frequency of placental accreta in our study $13.4 \%$ (66/492) and the number of cases were insufficient (22 patients). In our study, the incidence of placental accreta was high, which was inferred due to the fact that they were many patients with high risk factors for inducing placental accreta such as previous cesarean section, previous abortion, and so on[16,17]. The high incidence of placental accreta and another factor that our three hospitals were all referred hospitals maybe increased the incidence of placental previa $(1.5 \%)$.

Hasegawa et al. compared 26 placenta previa patients with massive hemorrhage $(\geq 2500 \mathrm{~mL})$ and 101 placental previa patients without, and reported that the distance of the internal os was not associated with intraoperative bleeding. Massive hemorrhage occurred in cases with the placenta located in the anterior portion (OR 3.5; 95\% CI 1.1-11.2), and accreta was also abundant (OR 15.1, 95\% CI 2.3-100.6), which is in agreement with our results[9].

Factors such as old age, multiparity, previous abortion, previous cesarean section are frequently associated with placenta previa. They are accounted as risk factors of excessive bleeding and peripartum hysterectomy, even if placenta previa does not exist $[3,6,9]$. Therefore Faiz et al. claimed that age, parity, history of cesarean section and history of abortion should be adjusted when demographic investigation on placenta previa is pursued [1].

In our study, in addition, to evaluate the effect of the placental location beneath incision site on maternal morbidity considering complete previa together, it was also adjusted by multivariate logistic regression analysis. The result was when the placenta located beneath the incision site, the incidence of excessive blood loss, massive transfusion, placental accreta and hysterectomy significantly increased.

This implies that in placental previa patients, the location of placenta beneath incision site is a risk factor of maternal morbidity independent of complete previa.

Placental accreta itself can raise the maternal morbidity rate as report by Usta et al. Therefore we adjusted placental accreta together by multivariate logistic regression analysis. The result (do not seen in tables) is that excessive blood loss (OR 2.38; 95\% CI: $1.26-4.49, p$ value 0.008 ) was affected by anterior placental location independent of placental accreta but massive transfusion (OR 2.40; 95\% CI 0.89-6.43, $P=$ 0.083 ) and hysterectomy were $\operatorname{not}(\mathrm{OR} 1.80 ; 95 \% \mathrm{CI}$ $0.62-5.23, P=0.282)$. It thus speculated that high incidence of placental accreta in the anterior group affected the increased the risk of massive transfusion and hysterectomy.

Further prospective studies including other sonographic markers of massive hemorrhage or adherence of placenta such as extensive vascular lakes [18], heterogeneity of placenta, loss of myometrial zone [19], sponge-like cervix and marginal sinus [9] could be required and it will give us more information about the relationship of anterior placenta with accreta or massive bleeding and finally it enables more tailored management.

In conclusion, anterior previa is more common in patients with 2 or more prior cesarean section compared to no prior cesarean section and it is more dangerous than posterior previa in view of increasing maternal morbidity such as excessive blood loss, massive transfusion, placental accreta and hysterectomy.

Therefore, sonographic detection of anterior placenta is very important to predict maternal outcomes in placental previa, and in such cases obstetricians should be aware of high possibility of maternal massive hemorrhage.

\section{Conflict of Interest}

The authors have declared that no conflict of interest exists.

\section{References}

1. Faiz AS, Ananth CV. Etiology and risk factors for placenta previa: an overview and meta-analysis of observational studies. J Matern Fetal Neonatal Med. 2003; 13:175-90.

2. Zlatnik MG, Cheng YW, Norton ME, et al. Placenta previa and the risk of preterm delivery. J Matern Fetal Neonatal Med. 2007; 20:719-23.

3. Oya A, Nakai A, Miyake $H$, et al. Risk factors for peripartum blood transfusion in women with placenta previa: a retrospective analysis. J Nippon Med Sch. 2008; 75:146-51.

4. Ohkuchi A, Onagawa T, Usui R, et al. Effect of maternal age on blood loss during parturition: a retrospective multivariate analysis of 10,053 cases. J Perinat Med. 2003; 31:209-15.

5. Bergholt T, Stenderup JK, Vedsted-Jakobsen A, et al. Intraoperative surgical complication during cesarean section: an observational study of the incidence and risk factors. Acta Obstet Gynecol Scand. 2003; 82:251-6.

6. Choi SJ, Song SE, Jung KL, et al. Antepartum risk factors associated with peripartum cesarean hysterectomy in women with placenta previa. Am J Perinatol. 2008; 25:37-41.

7. Bahar A, Abusham A, Eskandar M, et al. Risk factors and pregnancy outcome in different types of placenta previa. J Obstet Gynaecol Can. 2009; 31:126-31.

8. Zaki ZM, Bahar AM, Ali ME, et al. Risk factors and morbidity in patients with placenta previa accreta compared to placenta previa non-accreta. Acta Obstet Gynecol Scand. 1998; 77:391-4. 
9. Hasegawa J, Matsuoka R, Ichizuka K, et al. Predisposing factors for massive hemorrhage during Cesarean section in patients with placenta previa. Ultrasound Obstet Gynecol. 2009; 34:80-4.

10. Dola CP, Garite TJ, Dowling DD, et al. Placenta previa: does its type affect pregnancy outcome? Am J Perinatol. 2003; 20:353-60.

11. Ogawa M, Sato A, Yasuda K, et al. Cesarean section by transfundal approach for placenta previa percreta attached to anterior uterine wall in a woman with a previous repeat cesarean section: case report. Acta Obstet Gynecol Scand. 2004; 83:115-6.

12. Boehm FH, Fleischer AC, Barrett JM. Sonographic placental localization in the determination of the site of uterine incision for placenta previa. J Ultrasound Med. 1982; 1:311-4.

13. Tuzovic L. Complete versus incomplete placenta previa and obstetric outcome. Int J Gynaecol Obstet. 2006; 93:110-7.

14. Frederiksen MC, Glassenberg R, Stika CS. Placenta previa: a 22-year analysis. Am J Obstet Gynecol. 1999; 180:1432-7.

15. Usta IM, Hobeika EM, Musa AA, et al. Placenta previa-accreta: risk factors and complications. Am J Obstet Gynecol. 2005; 193:1045-9.

16. Miller DA, Chollet JA, Goodwin TM. Clinical risk factors for placenta previa-placenta accreta. Am J Obstet Gynecol. 1997; 177:210-4.

17. Belfort MA. Placenta accreta. Am J Obstet Gynecol. 2010; 203:430-9.

18. Comstock $\mathrm{CH}$, Love JJJr, Bronsteen RA, et al. Sonographic detection of placenta accreta in the second and third trimesters of pregnancy. Am J Obstet Gynecol. 2004; 190:1135-40.

19. Comstock $\mathrm{CH}$. Antenatal diagnosis of placenta accreta: a review. Ultrasound Obstet Gynecol. 2005; 26:89-96. 